\title{
Comprehensive Study of Forward and Fly Back Converter for Improvement in Performance
}

\author{
Gaurav B. Patil ${ }^{1}$, Paresh Shah ${ }^{2}$ \\ ${ }^{1}$ M.E Electrical scholar, SSBTees, Jalgaon, India \\ ${ }^{2}$ Professor, Department SSBT, Jalgaon, India
}

\begin{abstract}
This paper presents a comprehensive basic study of forward and fly back converter on the basis of performance characteristics such as power factor, efficiency, offset current, core loss etc. the forward and fly back topologies having its own advantages and disadvantages. To overcome limitations of converters comparative performance parameter analysis is done through observation and discuss. This discussion conclude that this can be achieved by combining both of topology together by using some suitable switching devices such as MOSFET which has special feature of low switching time. In This paper the merging of forward and fly back converter proposed topologies is also discussed. For high efficiency and high power factor single stage balanced forward- fly back converter.
\end{abstract}

Keywords: forward-fly back; MOSFET

\section{Introduction}

The function of a power converter is to process and control the flow of electric energy by supplying voltages and currents in a form that is optimally suited for the user loads.

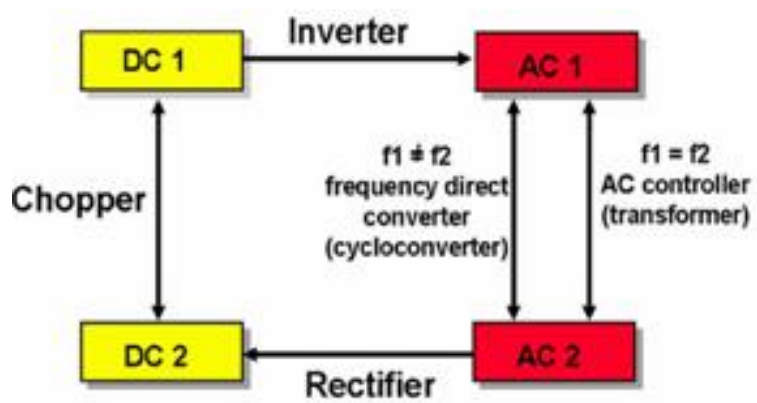

Figure 1: Classification of converter

Fig.1. shows classification of converter. Fly back converter is the most commonly used SMPS circuit for low output power application. Forward converter is another popular switched mode power supply (SMPS) circuit that is for producing isolated dc voltage from the unregulated dc input supply.

\section{Operation Principles}

A) Concept of flyback converter: - The fly back converter is based on the buck-boost converter. Fig. 2(a) depicts the basic buck-boost converter, with the switch realized using a MOSFET and diode. In Fig. 2(b), the inductor winding is constructed using two wires, with a 1:1 turn ${ }^{\text {ee }}$ ratio. Th e basic function of the inductor is unchanged, and the parallel windings are equivalent to a single winding constructed of larger wire. In Fig. 2(c), the connections between the two windings are broken. One winding is used while the transistor Q1 conducts, while the other winding is used when diode $D 1$ conducts. The total current in the two windings is unchanged from the circuit of Fig. 2(b); however, the current is now distributed between the windings differently. The magnetic fields inside the inductor in both cases are identical. Although the two-winding magnetic device is Represented using the same symbol as the transformer, a more descriptive name is "two winding inductor". This device is sometimes also called a "fly back transformer". Unlike the ideal transformer, current does not flow simultaneously in both windings of the fly back transformer. Fig. 2(d) illustrates the usual configuration of the fly back converter. The MOSFET source is connected to the primaryside ground, simplifying the gate drive circuit. The transformer polarity marks are reversed, to obtain a positive output voltage. A 1: $n$ turns ratio is introduced; this allows better converter optimization.

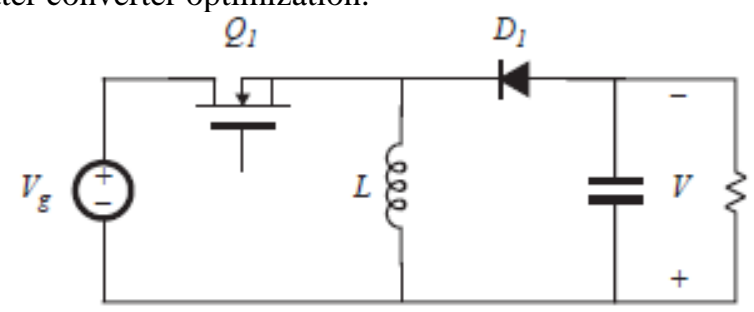

(a) A buck boost converter

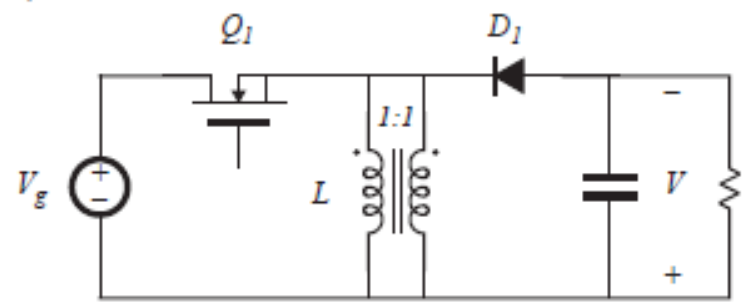

(b) Inductor L is wound with two parallel wires

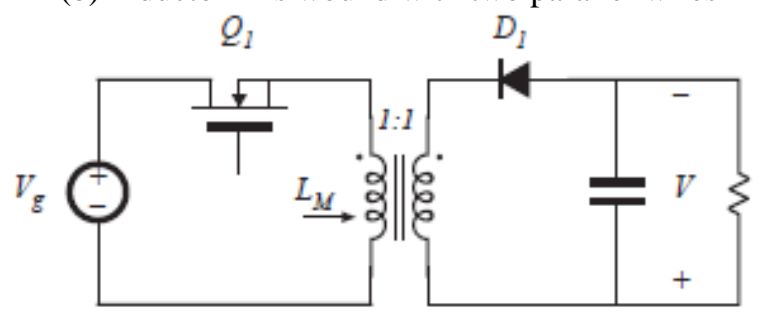

(c) Inductor winding are isolated leading to fly back converter 


\section{International Journal of Science and Research (IJSR) \\ ISSN (Online): 2319-7064}

Index Copernicus Value (2013): 6.14 | Impact Factor (2014): 5.611

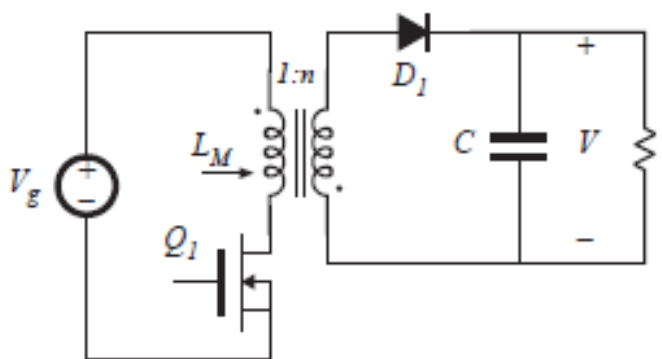

(d) With turns 1: $\mathrm{n}$ ratio and positive output

Figure 2: Configurations of the fly back converter

\section{B) Analysis of Flyback Converter}

The behavior of most transformer-isolated converters can be adequately understood by modeling the physical transformer with a simple equivalent circuit consisting of an ideal transformer in parallel with the magnetizing inductance. The magnetizing inductance must then follow all of the usual rules for inductors; in particular, volt-second balance must hold when the circuit operates in steady-state. This implies that the average voltage applied across every winding of the transformer must be zero. Let us replace the transformer of Fig. 2 with the equivalent circuit described above. The circuit of Fig.3(a) is then obtained. The magnetizing inductance $L M$ functions in the same manner as inductor $L$ of the original buck-boost converter of Fig. 2(a) when transistor $Q 1$ conducts, energy from the dc source $V g$ is stored in $L M$. When diode $D 1$ conducts, this stored energy is transferred to the load, with the inductor voltage and current scaled according to the $1: n$ turns ratio.

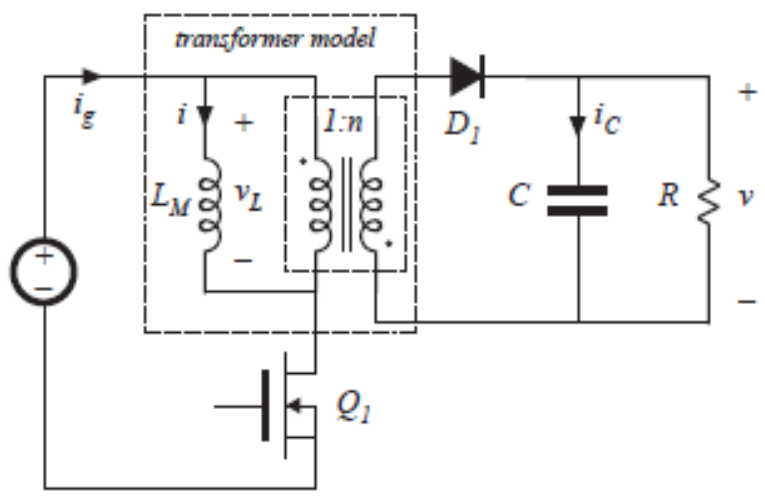

(a) Fly back converter transformer equivalent circuit model

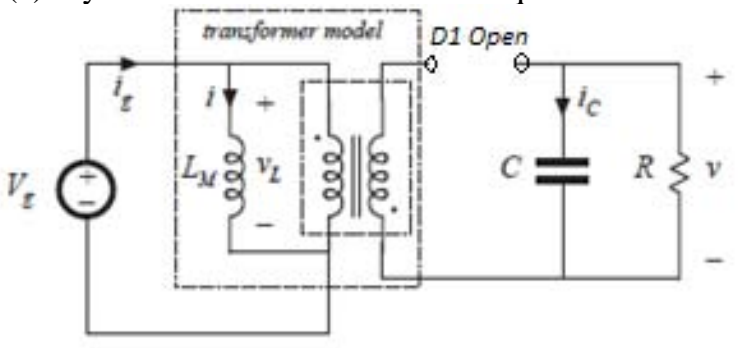

(b) When diode D1 in Open state

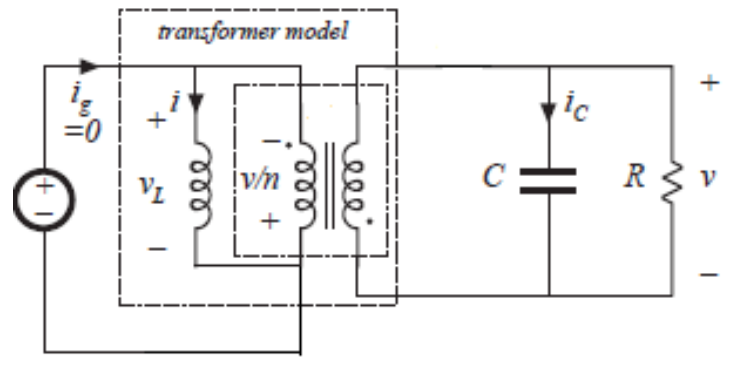

Figure 3: (c) When diode D2 in conducting state Equivalent Fly back converter circuits

\section{C) Concept of forward converter}

Forward converter is another popular switched mode power supply (SMPS) circuit that is used for producing isolated and controlled dc voltage from the unregulated dc input supply.

The forward converter, when compared with the fly-back circuit, is generally more energy efficient and is used for applications requiring little higher power output (in the range of 100 watts to 200 watts). However the circuit topology, especially the output filtering circuit is not as simple as in the fly-back converter Fig.4 shows the basic topology of the forward converter. It consists of a fast switching device , $S^{\text {ee }}$ along with its control circuitry, a transformer with its primary winding connected in series with switch ,See to the input supply and a rectification and filtering circuit for the transformer secondary winding. The load is connected across the rectified output of the transformer-secondary.

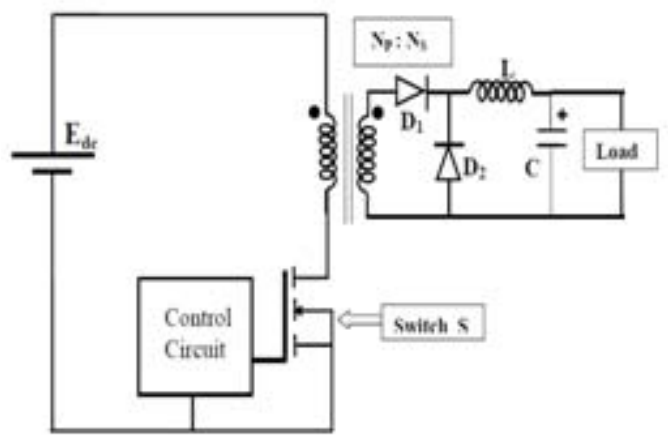

Figure 4: Basic forward converter topology

The transformer used in the forward converter is to be an ideal transformer with no leakage fluxes, zero magnetizing current and no losses. The basic operation of the circuit is explained with different mode operation here assuming ideal circuit elements. In fact, due to the presence of finite magnetizing current in a practical transformer, tertiary winding needs to be introduced in the transformer and the circuit topology changes slightly.

\section{Analysis of the forward converter Mode-1 circuit operation:}

Mode-1 of circuit starts after switch , $S^{\text {ee }}$ (as shown in Fig.4) is turned $\mathrm{ON}$. This connects the input voltage, $\mathrm{E}_{\mathrm{dc}}$, to the primary winding. Both primary and secondary windings start conducting simultaneously with the turning on of the switch. The primary and secondary winding currents and voltages 


\section{International Journal of Science and Research (IJSR) \\ ISSN (Online): 2319-7064}

Index Copernicus Value (2013): 6.14 | Impact Factor (2014): 5.611

are related to their turns-ratio $\left(\mathrm{N}_{\mathrm{p}} / \mathrm{N}_{\mathrm{s}}\right)$, as in an ideal transformer. Fig.5 (a) shows, in bold lines, the current carrying path of the circuit and Fig.5 (b) shows the functional equivalent circuit of mode-1. As switch „S $\mathrm{S}^{\text {ee }}$ closes, diode $\mathrm{D}_{1}$ in the secondary circuit gets forward biased and the input voltage, scaled by the

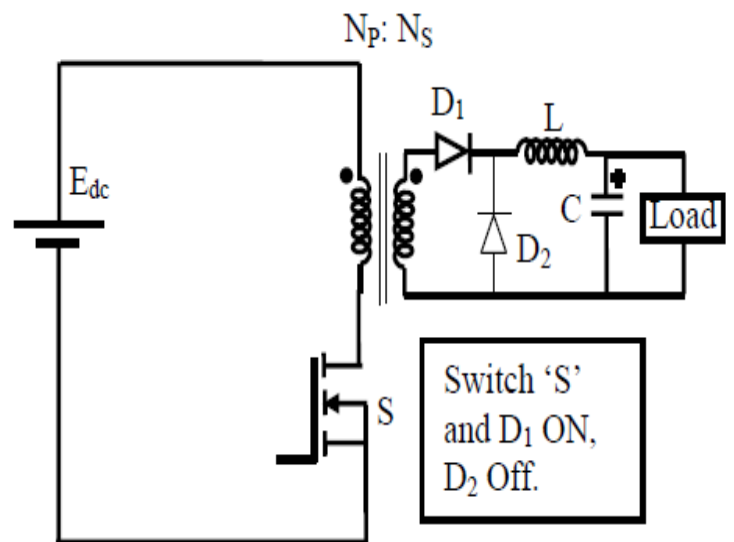

(a) Current path for Mode -1

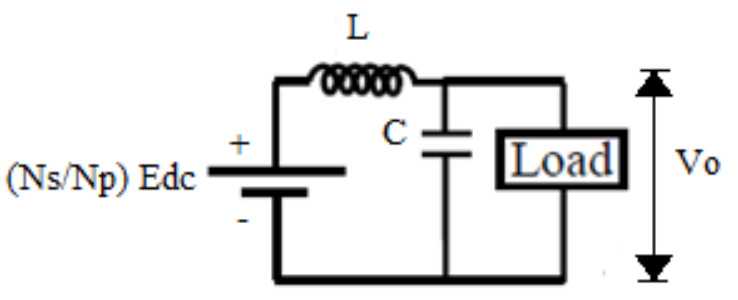

(b) Equivalent circuit in Mode-1

Figure 5: Mode-1 operation of forward converter

Transformer turns the input voltage, scaled by the transformer turns ratio, gets applied to the secondary circuit. Diode $\mathrm{D}_{2}$ does not conduct during mode- 1 , as it remains reverse biased.

\section{Mode-2circuit operation:}

As soon as switch ,S $S^{e e}$ is turned off. The primary and the secondary winding currents of the transformer fall to zero. However, the secondary side filter inductor maintains a continuous current through the freewheeling diode, $\mathrm{D}_{2}$ " Diode, $\mathrm{D}_{1}^{\text {ee }}$ remains off during this mode and isolates the output section of the circuit from the transformer and the input.

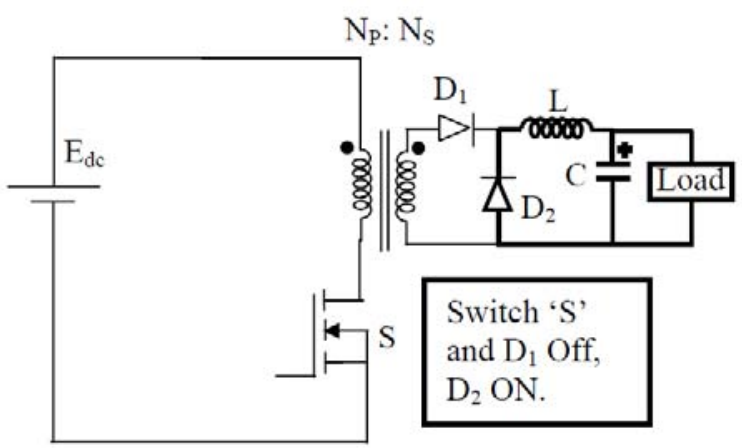

(a) Current path during Mode-2

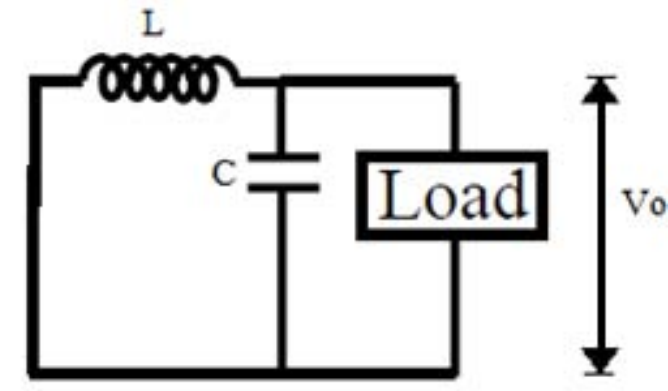

(b) Equivalent circuits in mode-2

Figure 6: Mode-2 operation of forward converter

Fig.6 (a) shows the current carrying portion of the circuit in bold line and Fig.6 (b) shows the equivalent circuit active during mode-2. Points , $\mathrm{P}^{\mathrm{ee}}$ and, $\mathrm{N}^{\mathrm{ee}}$ of the equivalent circuit are effectively shorted due to conduction of diode, $\mathrm{D}_{2}{ }^{\text {ee }}$. The inductor current continues to flow through the parallel combination of the load and the output capacitor. During mode-2, there is no power flow from source to load but still the load voltage is maintained nearly constant by the large output capacitor , ,Ce. The charged capacitor and the inductor provide continuity in load voltage. However since there is no input power during mode-2, the stored energy of the filter inductor and capacitor will be slowly dissipating in the load and hence during this mode the magnitudes of inductor current and the capacitor voltage will be falling slightly. In order to keep the load voltage magnitude within required tolerance band, the converter-switch , $S^{\mathrm{ec}}$ is turned on again to end the freewheeling mode and start the next powering mode (mode-1).

\section{Observation and Discussion}

Table 1: Observation table of Comparison between forward and fly back converter

\begin{tabular}{|c|c|c|}
\hline Characteristics & $\begin{array}{c}\text { Conventional fly } \\
\text { back converter }\end{array}$ & $\begin{array}{c}\text { Conventional } \\
\text { forward converter }\end{array}$ \\
\hline Power factor & High & Low \\
\hline Power conversion efficiency & Low & High \\
\hline Core losses & Large & Small \\
\hline Offset current & High & Low \\
\hline
\end{tabular}

From above table 1 . It is clear that advantage and disadvantage of fly back and forward converter are exactly oppositely of each other. It means the problem due to any one of them can be overcome by other. To solve all these problems, a high efficiency and high power factor singlestage balanced forward-fly back converter is proposed as shown in Fig. 7. Since the proposed converter merges the forward and fly back topologies, it can operate as the forward and fly back converters during switch turn-on and off periods, respectively. Therefore, it cannot only perform the power transfer during an entire switching period but also achieve the high power factor. Especially, since the charge balanced capacitor $\mathrm{Cb}$ can make the proposed converter perform the forward operation regardless of the input voltage, the magnetizing inductor offset current, core loss and transformer size can be minimized. 


\section{International Journal of Science and Research (IJSR) \\ ISSN (Online): 2319-7064 \\ Index Copernicus Value (2013): 6.14 | Impact Factor (2014): 5.611}

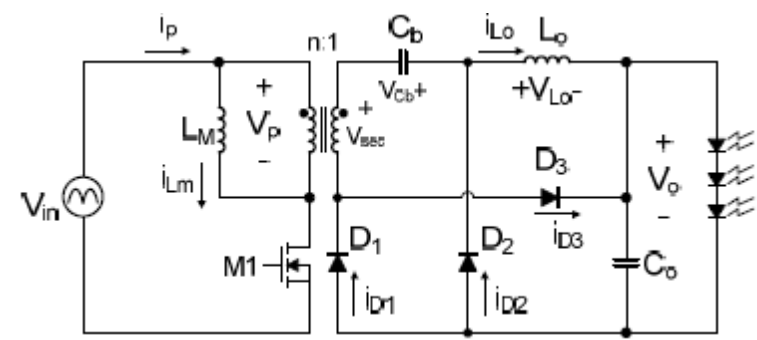

Figure 7: Circuit diagram of the proposed forward fly back converter

\section{Analysis of the Proposed Converter}

The magnetizing inductor offset current of fly back and forward converter is

$$
\begin{gathered}
<i L M, \text { flyback }>=\frac{\mathrm{I}_{\circ}}{\mathrm{n}(1-\mathrm{D})} \\
<i L M, \text { farward }>=\left(1+\frac{\mathrm{Nc}}{\mathrm{Np}}\right) \frac{\mathrm{Vin}}{2 \mathrm{LM}} D^{\wedge} 2 T s
\end{gathered}
$$

Moreover, from equations (1) and (2), while the magnetizing inductor offset current of fly back converter is dependent on the load current Io, that of forward converter is not. Therefore, as the load current is more increased, the offset current of fly back converter becomes larger, which might result in the larger core loss and volume of transformer. For these reasons, the forward converter is superior to the fly back converter in terms of the transformer size and energy conversion efficiency.

\section{A. Voltage Conversion Ratio}

The voltage conversion ratio of the proposed converter can be obtained by applying the volt-second balance rule on $\mathrm{L}_{\mathrm{M}}$ and Lo. the voltage across $L_{M}$ is $V_{\text {in }}$ and $n\left(V_{o}+V_{c b}\right)$ during $\mathrm{t}_{1}-\mathrm{t}_{0}=\mathrm{DTs}$ and $\mathrm{t}_{2}-\mathrm{t}_{1}=(1-\mathrm{D}) \mathrm{Ts}$, respectively. Therefore, following equation can be obtained.

$$
\mathrm{D} \mathrm{V}_{\text {in }}=\mathrm{n}\left(\mathrm{V}_{0}+\mathrm{V}_{\mathrm{cb}}\right) \cdot(1-\mathrm{D})
$$

Where $\mathrm{D}$ and $\mathrm{T}_{\mathrm{s}}$ are operating duty ratio and one switching cycle, respectively. Similarly, the voltage across $\mathrm{L}_{0}$ is $\mathrm{V}_{\text {in }} / \mathrm{n}$ $+\mathrm{V}_{\mathrm{cb}}-\mathrm{V}_{\mathrm{o}}$ and $\mathrm{V}_{\mathrm{o}}$ during $\mathrm{t}_{1}-\mathrm{t}_{\mathrm{o}}=\mathrm{DT}_{\mathrm{S}}$ and $\mathrm{t}_{2}-\mathrm{t}_{1}=$ (1-D) Ts, respectively. Therefore, following equation can also be obtained.

$$
V=\frac{\text { DVin }}{\mathrm{n}}+\mathrm{DVcb}
$$

Combining equations (3) and (4) gives the voltage $\mathrm{V}_{c b}$ across the balancing capacitor $\mathrm{C}_{\mathrm{b}}$ as

$$
\mathrm{V}_{\mathrm{cb}}=\mathrm{DV}_{\mathrm{o}}=\frac{\mathrm{D}^{\wedge} 2}{\mathrm{n}\left(1-\mathrm{D}^{\wedge} 2\right)} \operatorname{Vin}
$$

From equation (3) and (5), the output voltage $V_{0}$ can be obtained as

$$
V=\frac{\text { DVin }}{\mathrm{n}\left(1-\mathrm{D}^{\wedge} 2\right)}
$$

\section{B. Voltage stress of switch and diode}

As mentioned earlier, when $M_{1}$ is turned off, the voltage $V_{D S}$ across $M_{1}$ is the sum of input voltage $V_{\text {in }}$ and reflected voltage $\mathrm{n}\left(\mathrm{V}_{\mathrm{o}}+\mathrm{V}_{\mathrm{cb}}\right)$ to the transformer primary side. Therefore, the voltage stress of $\mathrm{M}_{1}$ can be represented by

$$
\mathrm{V}_{\mathrm{DS} \text {, stress }}=\mathrm{V}_{\text {in }}+\mathrm{n}\left(\mathrm{V}_{\mathrm{o}}+\mathrm{V}_{\mathrm{cb}}\right)
$$

$\mathrm{D}_{1}$ and $\mathrm{D}_{3}$ among three output diodes are clamped on Vo. Therefore, their voltage stresses are determined by $\mathrm{V}_{\mathrm{o}}$. When the switch M1 is conducting, the voltage stress of D2 is expressed by

$$
\text { VD2, stress }=\frac{\text { Vin }}{n}+V c
$$

Fig.8 shows comparisons of voltage stresses according to the transformer turn ratio $\mathrm{n}$ between conventional fly back and proposed forward-fly back converters.[1] For the convenience of comparative analysis, input and output specifications are assumed as $\mathrm{V}_{\text {in }}=90 \sim 264 \mathrm{~V}_{\text {rms }}$ and $\mathrm{V}_{\mathrm{o}}=42$ $\mathrm{V}$. As can be seen in this figure, the higher turn ratio can more decrease the diode voltage stress but more increase the switch voltage stress, and vice versa. Especially, the switch voltage stress of the proposed converter is somewhat higher than that of the conventional one due to the balanced capacitor voltage $V_{c b}$. Therefore, in designing the transformer turn ratio, the switch voltage stress must be carefully considered.

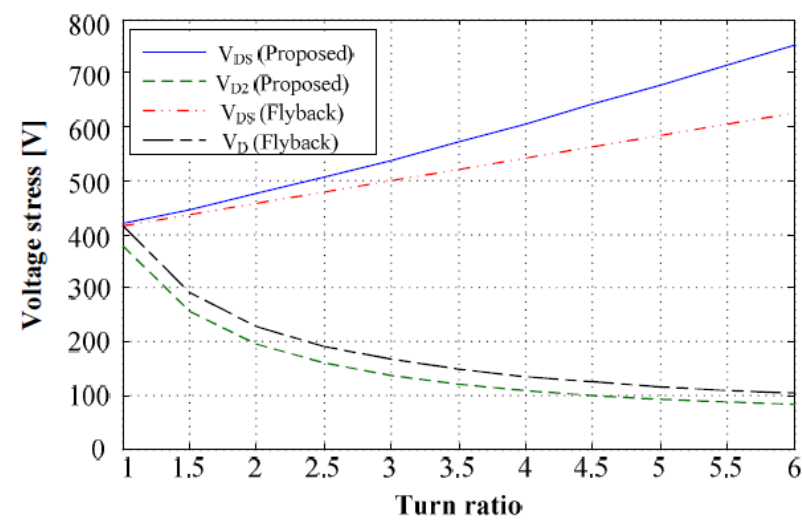

Figure 8: Comparisons of voltage stresses between conventional fly back and proposed forward-fly back converters

The fly back converter is commonly used at the 50-100W power range, as well as in high voltage supplies power for televisions and computer monitors. It has the advantage of very low Parts count. Multiple outputs can be obtained using a minimum number of parts.

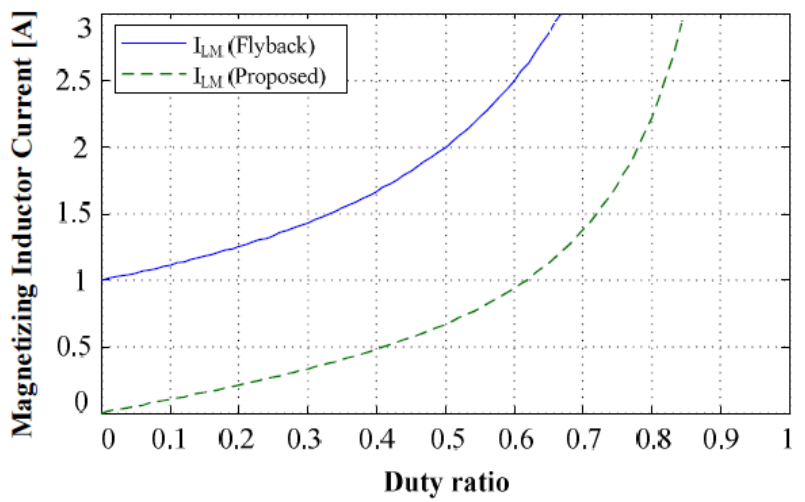

Figure 9: Magnetizing offset currents conventional fly back converter according to the operating duty ratio

\section{Offset current of magnetizing inductor}

The offset current of transformer magnetizing inductor generally determines the volume and core loss of the transformer. Therefore, the smaller offset current of $\mathrm{L}_{\mathrm{M}}$ is the better. The offset current $\mathrm{I}_{\mathrm{LM}}$ though transformer magnetizing inductor $\mathrm{L}_{M}$ can be calculated by the sum of average primary current $I_{p}$ and reflected average secondary current $\mathrm{I}_{\text {sec }} \mathrm{n}$ to the transformer primary side. Therefore, the conventional fly back converter has following offset current of $\mathrm{L}_{\mathrm{M}}$. 


\section{International Journal of Science and Research (IJSR) \\ ISSN (Online): 2319-7064}

Index Copernicus Value (2013): 6.14 | Impact Factor (2014): 5.611

Inductor magnetizing current,

$$
\mathrm{I}_{\mathrm{LM}}=\frac{1}{\mathrm{n}(1-\mathrm{D})} \text { Io }
$$

Where, $I_{0}$ is the average load current.

On the other hand, since the average current $I_{\text {sec }}$ of transformer secondary side is zero due to the serially connected balancing capacitor $\mathrm{C}_{\mathrm{b}}$, the offset current $\mathrm{I}_{\mathrm{LM}}$ though $\mathrm{L}_{\mathrm{M}}$ is equal to the average primary current $\mathrm{I}_{\mathrm{p}}$. Therefore, the proposed forward fly back converter has following offset current of Lm.

$$
<\mathrm{i}_{\mathrm{LM}}>=<\mathrm{i}_{\mathrm{p}}>=\frac{\mathrm{D}}{\mathrm{n}\left(1-\mathrm{D}^{2}\right)} \text { Io }
$$

Based on equations (9) and (10), the magnetizing offset currents of conventional fly back and proposed forward-fly back converters according to operating duty ratio are shown in Fig.9. For the convenience of comparative analysis, input and output specifications are assumed as $V_{\text {in }}=90 \sim 264$ Vrms, $\mathrm{V}_{\mathrm{o}}=42 \mathrm{~V}$ and $\mathrm{Io}=0.57 \mathrm{~A}$.

As shown in fig.9, the magnetizing offset current of the proposed converter is lower than that of the fly back converter with the aid of the balancing capacitor $C_{b}$. As a result, the proposed converter can achieve the smaller transformer core loss and higher efficiency.

\section{Conclusion}

A comprehensive study of forward and fly back concludes that when fly back converter operates independently. They can achieve better power factor with lower conversion efficiency whereas forward converter can able to achieve higher efficiency but having larger magnetizing offset current. Also has higher voltage stress. This entire problem can be overcome by proposed converter. The magnetizing offset current of the proposed converter is lower than that of the fly back converter with the aid of the balancing capacitor $\mathrm{C}_{\mathrm{b}}$. As a result, the proposed converter can achieve the smaller transformer core loss and higher efficiency. This discussion also leads to conclude that the switch voltage stress of the proposed converter is somewhat higher than that of the conventional one due to the balanced capacitor voltage $\mathrm{V}_{\mathrm{cb}}$. This also helps in improvement in individual performance of converter. Since the proposed converter merges the forward and fly back topologies by using MOSFET which having least switching time among all switching device, The proposed converter can operate as the forward and fly back converters during switch turn-on and off periods, respectively. Therefore, it cannot only perform the power transfer during an entire switching period but also achieve the high power factor.

\section{References}

[1] Yoon Choi, Moon-Hwan Keum, Sang Kyoo Han and Jeong-il Kang, "High efficiency and high power factor single-stage balanced forward-fly back converter" , IEEE, pp. 822-827, 2013

[2] Bhim Singh, Sanjeev Singh, Ambrish Chandra, and Kamal Al Haddad, "Comprehensive study of single phase AC- DC power corrected converter with high frequency isolation", IEEE Trans. On industrial informatics, vol.7, no.4, pp. 540-556, Nov. 2011

[3] F. Xiao Yun, L. Xiaojian, and W. Yan, "Research and analysis of the design development and prospective technology for LED lighting products," in proceeding of CAID \& CD, pp. 1330-1334, Nov. 2009

[4] Yungtaek Jang and Milan M. Jovanovich, "Bridgeless High power factor Buck converter," IEEE Trans. Power electron, vol.26, pp. 602-611, Feb 2011

[5] Subhra jyoti Modak , Goutam Kumar Panda, Pradip Kumar Saha and Sanskar Das, "Design of Novel fly-back converter using PID controller" IJAREEIE, Vol. 4 ,pp. 289-297, Jan 2015

[6] Abhinav Dogra, Kanchan Pal, "Designing and tunning of PI controller for fly back converter ", IJETT, vol.13, no.3, Jul 2014

[7] Jing Wang, "Mixed-signal-Controlled Fly backtransformer based converter with improved Dynamic performance and transient energy recycling", IEEE power electronics, vol. 28, no. 2,Feb 2013

[8] Ramon Silva- ortigoza, Victor Manuel Hernandezguzman, Maryacruz and Daniel, "DC/DC Buck Power Converter as a smooth starter for a DC motor based on a Hierarchical Control", IEEE Trans. power electronics, vol. 30, no.2, Feb 2015 